\title{
Factors contributing to the reduction in childhood stunting in Bangladesh: a pooled data analysis from the Bangladesh demographic and health surveys of 2004 and 2017-18
}

Pradeep Kumar, Rashmi Rashmi®, T. Muhammad and Shobhit Srivastava*

\begin{abstract}
Background: Over the last two decades, Bangladesh has made progress in reducing the percentage of stunted children under age 5 years from 51\% in 2004 to 31\% in 2017. Such reduction has created a source for new research to understand its contributing factors. The present study aims to identify such crucial factors which contributed in reducing the percentage of under-five stunting status of children from 2004 to 2017-18.

Methods: The study used data from the Bangladesh Demographic and Health Surveys (BDHS), conducted in 2004 and in 2017-18, focused on children under-5-years of age (U5). The sample sizes were $n=6375$ children included in the 2004 survey and $n=8312$ children included in the 2017-18 survey. Descriptive analysis and bivariate analysis were conducted for a general characterization of the samples. Logistic regression was used to find out the significant factors contributing to the prevalence of stunting among U5 children. Furthermore, the Fairlie decomposition technique was used to identify the crucial factors that contributed to the reduction of stunting.

Results: The prevalence of stunting among U5 children has declined significantly, from 49.8 to $30.7 \%$ between the two survey periods (2004 and 2017-18). Estimates of decomposition analysis show that overall, the selected variables explained $50.6 \%$ of the decrease in the prevalence of stunting. Mother's characteristics such as age at first birth, education level, working status and BMI (body mass index) status were the primary contributors of this change. Father's characteristics, such as education explained $9 \%$ of this change.

Conclusion: The results of the study highlight the importance of increasing maternal education and reducing interhousehold wealth inequality to improve nutritional status of U5 children. In order to achieve further reduction in stunting, among U5 children in Bangladesh, this paper calls for policymakers to develop effective programs to improve maternal education, raise parental awareness of parents regarding children's height and weight, and aim to significantly reduce inter-household inequalities.
\end{abstract}

Keywords: Stunting, Decadal change, Under-5-y children, Bangladesh

* Correspondence: shobhitsrivastava889@gmail.com

International Institute for Population Sciences, Mumbai, Maharashtra 400088, India

C C The Author(s). 2021 Open Access This article is licensed under a Creative Commons Attribution 4.0 International License, which permits use, sharing, adaptation, distribution and reproduction in any medium or format, as long as you give appropriate credit to the original author(s) and the source, provide a link to the Creative Commons licence, and indicate if changes were made. The images or other third party material in this article are included in the article's Creative Commons licence, unless indicated otherwise in a credit line to the material. If material is not included in the article's Creative Commons licence and your intended use is not permitted by statutory regulation or exceeds the permitted use, you will need to obtain permission directly from the copyright holder. To view a copy of this licence, visit http://creativecommons.org/licenses/by/4.0/. The Creative Commons Public Domain Dedication waiver (http://creativecommons.org/publicdomain/zero/1.0/) applies to the data made available in this article, unless otherwise stated in a credit line to the data. 


\section{Background}

Over the last two decades, different policies and programs have worked together to uplift the success of child survival across the globe [1-4]. Despite these improvements, deprivation from adequate nutrition along with recurrent illness among children has paved the way for a critical health issue [5-7]. Stunting, defined by the WHO [8] as "impaired growth and development that children experiences from poor nutrition, repeated infection and inadequate psychosocial simulation" is one of the grratest child health challenges which leaves a lifelong mark on the individual $[6,7]$.

Globally, approximately 149 million children experience stunting before their fifth birthday [9]. The Global Overview Child Malnutrition Regional Trends Report of UNICEF shows that in Asia stunting still aflicts more than half of the Under-5 (U5) children (55\%. More specifically, the situation of children in South Asian countries is alarming. Bangladesh is one such country which has experienced, throughout the decades, many ups and downs in the prevalence of stunted children. Being in a frequent natural disaster-prone area, the possibility of infectious diseases and inadequate nutrition are higher among the population $[10,11]$. During the 1974 famine, the country experienced the highest (71\%) Under-5 rates of stunting [12]. This has decreased to $31 \%$ in 2017 [13]. The country had made remarkable progress in reducing the prevalence of stunting, but it is still far from the 15\% threshold marked by World Health Organization for an emergency situation in stunting for any country [14].

Extant research had repeatdly pointed out the prevalence of stunting in U5 children and its associated risk factors in Bangladesh [12, 15-20]. Studies have revealed that the effect of childhood stunting is long lasting and, in most cases, irreversible. Stunting is associated with lower mental capacity, slower cognitive development, and low school performance that will impact adult productivity. It is also related with an increase in mortality rates and an overall deteriotaon of the children's health status [6, 21-25]. And these challenges can further topple the growth and development of a family, society and country as a whole.

Stunting develops at very early age due to unhealthy environments experienced by both mother and child [25, 26]. Previous literature in Bangladesh has linked the risk of under-five stunting with socio-demographic, healthcare services and nutrition-related factors [15, 19, 27, 28]. Although focusing on nutrition and recurrent diseases among children have helped in improving their health, there is the necessity to focus on the first and foremost proximal setting of a child: the family. A community-level cross-sectional study also revealed that over $85 \%$ of main caregivers in Bangladesh households are mothers who play an influential role in arranging and providing food for their children [29]. A study, using multilevel approach, has clearly shown that the risk of stunting was higher among children whose parents have the lower educational level and poorest wealth index, if the age of mother at the birth of the first child was below 20 years and if child's age range was 36-47 months [16]. Furthermore, in Bangladesh research has highligthed the importance of improved water source and sanitation facility in a household towards child health [27, 30]. Moreover, even if the public health services are advanced, household wealth inequalityis strongly associated with childhood growth faltering [28]. Household wealth inequality measures the unequal economic distribution across the households which affects distinctly the food availability, access to health services, morbidity and mortality among the various sections of society. It was worth noting that children from the poorest household were thrice more likely to experience adverse stunting than those who reside in the wealthiest households. A cross country study has shown that, between 1997 and 2007, Bangladesh has recorded a fairly rapid progress against malnutrition among the low-andmiddle-income countries [31] and has sparked interest about which contributing determinants of this reduction are.

Therefore, the main goal of this study is to identify the crucial factors that contributed to the reduction of stunting among U5 children in Bangladesh, between 2004 and 2017-18. The rationale for this analysis is threefold: i) Over the years, nutritional commitments at global platform have helped the countries across the world either to achieve their desired goal or to move one step forward without achieving fully. Such success or failure of programs help to modify the strategies and policies of the government. A country like Bangladesh which has observed many ups and downs in under-5 stunting status, there a study which can provide a clear picture of potential drivers is the need-of-the-hour. Although the past evidence shows the determinants of under-5 stunting status of Bangladeshi children, there is need for recent evidence which this study brings out.; ii), ample evidence shows the association of lower stunting status of children with the higher education and wealth status of family [32]. Studies have also pointed towards the key role of sanitation and demographic factors as the drivers of change. However, minimal evidence shows the role of the mother's health on child stunting status, which have been explored in the present study; iii), with the limitations in nutrition-related information for under-five children in Bangladesh, this study pronounced to consider family (i.e. mother and father) and community related characteristics along with the household socio-economic and demographic factors. Thus, using two rounds of Bangladesh Demographic and 
Health Survey and Fairlie decomposition technique [33], this study explores the contributing factors of reduction in under-five stunting status in Bangladesh.

\section{Methods \\ Data}

This study utilized data from Bangladesh Demographic and Health Survey (BDHS), a nationally-representative survey conducted by the National Institute for Population Research and Training (NIPORT) of the Ministry of Health and Family Welfare [34, 35]. BDHS collected data on the nutritional status of children by measuring the height and weight of all children aged between 0 and 59 months in the selected households. The present study used two rounds of BDHS in 2004 and 2017-18 .

The sample for BDHS-2004 covered the entire population residing in private dwelling units in the country [35]. Administratively, Bangladesh is divided into six divisions. In turn, each division is divided into zilas, and each zila into upazilas. Each urban area in the upazila is divided into wards, and into mahallas within the ward; each rural area in the upazila is divided into union parishads (UP) and into mouzas within the Ups [35]. The urban areas were stratified into three groups, i) Standard metropolitan areas, ii) Municipality areas, and iii) Other urban areas. These divisions allow the country, as a whole, to be easily separated into rural and urban areas. For the 2001 census, subdivisions called enumeration areas (EAs) were created based on a convenient number of dwelling units. Because sketch maps of EAs were accessible, EAs were considered suitable to use as primary sampling units (PSUs) for the 2004 BDHS [35]. In each division, the list of EAs constituted the sample frame for the 2004 BDHS survey. The BDHS-2004 sample is a stratified, a multistage cluster sample consisting of 361 The primary sampling units (PSUs), were 122 in the urban areas and 239 in the rural areas [35]. After the target sample was allocated to each group area, according to urban and rural status, the number of PSUs was calculated in terms of an average of 28 completed interviews of eligible women per PSU (or an average of 30 selected households per PSU) [35].

The BDGS-2017-18 used a sampling frame from the list of enumeration areas (EAs) of the 2011 Population and Housing Census of the People's Republic of Bangladesh, provided by the Bangladesh Bureau of Statistics (BBS). The primary sampling unit (PSU) of the survey is an EA with an average of about 120 households. The survey is based on a two-stage stratified sample of households. In the first stage, 675 EAs (250 in urban areas and 425 in rural areas) were selected with probability proportional to EA size. In the second stage of sampling, a systematic sample of an average of 30 households per EA was selected to provide statistically reliable estimates of key demographic and health variables for the country as a whole, for urban and rural areas separately [34]. All methods were performed in accordance with the relevant guidelines and regulations.

The effective sample size for the analysis was 6375 and 8312 U5 children in Bangladesh for the years 2004 and 2017-18, respectively. Only children with data for height and weight were included in the analysis.

\section{Variable description \\ Outcome variable}

The outcome variable for the present study is stunting among U5 children in Bangladesh. Stunting was defined as height for age $<-2$ standard deviation (SD) from the median of the WHO growth standards [36].

\section{Explanatory variable}

The explanatory variables include different individual, household, socio-economic and demographic factors which have been shown to influence stunting status of U5 children [15-17, 19]. The variables were divided into four sections, for analysis purposes: i) mother characteristics, ii) father characteristics, ii) child characteristics and iv) household characteristics.

\section{Mother's characteristics}

Age at first birth was recoded as $0=$ less than 18 years and $1=18$ years or more, educational status was recoded as $0=$ not educated and $1=$ educated (completed primary education and above), working status was recoded as $0=$ not working and $1=$ working and low body mass index $(\mathrm{BMI})$ was recoded as $0=$ no $(\geq 18.5)$ and $1=$ yes $(<18.5)$.

\section{Father's characteristics}

Educational status was recoded as $0=$ not educated and 1 = educated (primary completed and above), working status was recoded as $0=$ not working and $1=$ working.

\section{Child's characteristics}

Child's age (in months) was recoded as $1=0-23,2=23-$ 47 and $3=48-59$, sex was recoded as $1=$ male and $2=$ female, birth order was recoded as $1=$ one, $2=$ two, $3=$ three and $4=$ four and above.

\section{Household characteristics}

Protected water source [36] was recoded as $0=$ no (Unprotected dug well, unprotected spring, cart with small tank/drum, tanker truck, and surface water (river, dam, lake, pond, stream, canal, irrigation channels), bottled water) and $1=$ yes (Public taps or standpipes, tube wells or boreholes, protected dug wells, protected springs and rainwater collection, Piped household water connection located inside the user's dwelling, plot or yard), 
improved toilet source [36] was recoded as $0=$ no (flush or pour-flush to elsewhere, pit latrine without slab or open pit, bucket, hanging toilet or hanging latrine and no facilities or bush or field (open defecation) and $1=$ yes (flush or pour-flush to piped sewer system, septic tank or pit latrine, ventilated improved pit latrine, pit latrine with slab and composting toilet), wealth index was recoded as $1=$ poorest, $2=$ poorer, $3=$ middle, $4=$ richer and $5=$ richest. The variable of wealth status was created using the information given in the survey. Households were given scores based on the number and kinds of consumer goods they own, ranging from a television to a bicycle or car, and housing characteristics such as source of drinking water, toilet facilities, and flooring materials. These scores are derived using principal component analysis [36]. National wealth quintiles are compiled by assigning the household score to each usual (de jure) household member, ranking each person in the household population by their score, and then dividing the distribution into five equal categories.

Religion was recoded as $1=$ Islam and $2=$ others, residential status was recoded as $1=$ urban and $2=$ rural. Regions were provided in the survey as $1=$ Barisal, $2=$ Chittagong, $3=$ Dhaka, $4=$ Khulna, $5=$ Rajshahi and $6=$ Sylhet. To be noted, BDHS 2017-18 had eight regions namely Barisal, Chittagong, Dhaka, Khulna, Mymensingh Rajshahi, Rangpur and Sylhet. For analytical reasons Mymensingh was merged in Dhaka and Rangpur was merged in Rajshahi as these were divided at certain points after 2004.

\section{Statistical analysis}

Descriptive analysis and bivariate analysis were conducted for a general characterization of the samples. Proportion test was used to reveal the significance level for the difference in the prevalence of stunting from 2004 to 2017-18. Logistic regression was used to find out the significant factors contributing to the prevalence of stunting among U5 children. Furthermore, fairlie decomposition technique was used to identify the crucial factors that contributed to the reduction of stunting. At first, the crude difference of stunting rates across the two samples were represented in the bivariate analysis; however to identify the difference and underlying causes of the decadal difference in the prevalence of stunting, the technique of decomposition was used identify and quantify inter-group differences. The original Blinder and Oxaca decomposition method is attributed to Blinder (1973) and Oaxaca (1973) who developed it to analyse continuous variables [37]. This technique, was extended and named "Fairlie decomposition" which is appropriate for binary models to decompose the decadal change in the prevalence stunting among children under age five years into contributions that can be attributed to different factors [33].

$$
\begin{aligned}
Y^{t 1}-Y^{t 2}= & {\left[\sum_{i=1}^{N^{t 1}} \frac{F\left(X_{i}^{t 1} \beta^{t 2}\right)}{N^{t 1}}-\sum_{i=1}^{N^{t 2}} \frac{F\left(X_{i}^{t 2} \beta^{t 2}\right)}{N^{t 2}}\right] } \\
& +\left[\sum_{i=1}^{N^{t 1}} \frac{F\left(X_{i}^{t 1} \beta^{t 1}\right)}{N^{t 1}}-\sum_{i=1}^{N^{t 1}} \frac{F\left(X_{i}^{t 1} \beta^{t 2}\right)}{N^{t 1}}\right]
\end{aligned}
$$

Where $\mathrm{Y}$ is the dependent variable (stunting) at time t1 (2004) and t2 (2017-18), $N^{J}$ is the sample size for time t, $X^{J}$ is the row vector of average values of the independent variable and $\beta^{J}$ is the vector of coefficient estimates for time t. This method of decomposition allows us to quantify the absolute contribution of factors explaining the decadal change (2004 to 2017-18) in the probability of U5 Bangladeshi children being stunted. Further, using mean variance inflation factor (VIF), we found no evidence of multicollinearity among the exaplantory variables. STATA 14 was used to carry out the analysis for the present study [38].

\section{Results}

Socio-economic and demographic profile of the mothers (Table 1)

The proportion of women who got married at age 18 or older increased from 39.8 to $56.8 \%$ between 2004 and 2017-18. There was a increase in the women's educational status (30 percentage point) during these two survey periods. Similarly, the proportion of working women also increased from 17.6 to $42.4 \%$ between 2004 and 2017-18. There was a decline of low BMI women (from 38.4 to $15.3 \%$ ). Conversely, the use of protected water declined slightly (from 96.7 to $85.4 \%$ ) whereas the percentage of improved toilet facility increased from $56.7 \%$ to $57.8 \%$ between two survey periods.

\section{Prevalence of stunting among children under five years (Table 2)}

Results revealed that there was a significant decline (from $49.8 \%$ to $30.7 \%$ ) in the prevalence of stunting among children age below 5 years in Bangladesh bewteen two survey periods (2004 and 2017-18). The decline in the prevalence of stunting was observed in all background characteristics (included mother, husband, child and household's characteristics).

Figure 1 revealed that overall the prevalence of stunting among children had declined by 19 percentage point. Moreover, the highest decline was observed in Dhaka followed by Barisal and Chittagong. 
Table 1 Socio-economic and demographic profile of study population in Bangladesh

\begin{tabular}{|c|c|c|c|c|}
\hline \multirow{2}{*}{$\begin{array}{l}\text { Background } \\
\text { characteristics }\end{array}$} & \multicolumn{2}{|l|}{2004} & \multicolumn{2}{|c|}{ 2017-18 } \\
\hline & Sample & Percentage & Sample & Percentage \\
\hline \multicolumn{5}{|l|}{ Mother's characteristics } \\
\hline \multicolumn{5}{|l|}{ Age at first birth } \\
\hline Less than 18 years & 3836 & 60.2 & 3589 & 43.2 \\
\hline 18 years or more & 2539 & 39.8 & 4723 & 56.8 \\
\hline \multicolumn{5}{|l|}{ Educational status } \\
\hline Not educated & 2396 & 37.6 & 594 & 7.2 \\
\hline Educated & 3979 & 62.4 & 7718 & 92.8 \\
\hline \multicolumn{5}{|l|}{ Working status } \\
\hline Not working & 5256 & 82.5 & 4786 & 57.6 \\
\hline Working & 1119 & 17.6 & 3526 & 42.4 \\
\hline \multicolumn{5}{|l|}{ Low BMI } \\
\hline No & 3930 & 61.7 & 7041 & 84.7 \\
\hline Yes & 2445 & 38.4 & 1271 & 15.3 \\
\hline \multicolumn{5}{|l|}{ Father's characteristics } \\
\hline \multicolumn{5}{|l|}{ Educational status } \\
\hline Not educated & 2556 & 40.1 & 1216 & 14.6 \\
\hline Educated & 3819 & 59.9 & 7096 & 85.4 \\
\hline \multicolumn{5}{|l|}{ Working status } \\
\hline Not working & 79 & 1.2 & 184 & 2.2 \\
\hline Working & 6296 & 98.8 & 8128 & 97.8 \\
\hline \multicolumn{5}{|l|}{ Child's characteristics } \\
\hline \multicolumn{5}{|c|}{ Children age (in months) } \\
\hline $0-23$ & 2503 & 39.3 & 3452 & 41.5 \\
\hline $23-47$ & 2605 & 40.9 & 3244 & 39.0 \\
\hline $48-59$ & 1267 & 19.9 & 1616 & 19.4 \\
\hline \multicolumn{5}{|l|}{ Sex } \\
\hline Male & 3237 & 50.8 & 4335 & 52.2 \\
\hline Female & 3138 & 49.2 & 3977 & 47.8 \\
\hline \multicolumn{5}{|l|}{ Birth order } \\
\hline 1 & 1830 & 28.7 & 3185 & 38.3 \\
\hline 2 & 1635 & 25.6 & 2683 & 32.3 \\
\hline 3 & 1162 & 18.2 & 1408 & 16.9 \\
\hline 4 and above & 1748 & 27.4 & 1036 & 12.5 \\
\hline \multicolumn{5}{|c|}{ Household characteristics } \\
\hline \multicolumn{5}{|c|}{ Protected water source } \\
\hline No & 212 & 3.3 & 1215 & 14.6 \\
\hline Yes & 6163 & 96.7 & 7097 & 85.4 \\
\hline \multicolumn{5}{|c|}{ Improved toilet facility } \\
\hline No & 2759 & 43.3 & 3509 & 42.2 \\
\hline Yes & 3616 & 56.7 & 4803 & 57.8 \\
\hline \multicolumn{5}{|l|}{ Wealth Index } \\
\hline Poorest & 1604 & 25.2 & 1782 & 21.4 \\
\hline Poorer & 1323 & 20.8 & 1690 & 20.3 \\
\hline
\end{tabular}


Table 1 Socio-economic and demographic profile of study population in Bangladesh (Continued)

\begin{tabular}{|c|c|c|c|c|}
\hline \multirow{2}{*}{$\begin{array}{l}\text { Background } \\
\text { characteristics }\end{array}$} & \multicolumn{2}{|l|}{2004} & \multicolumn{2}{|l|}{ 2017-18 } \\
\hline & Sample & Percentage & Sample & Percentage \\
\hline Middle & 1244 & 19.5 & 1568 & 18.9 \\
\hline Richer & 1150 & 18.0 & 1653 & 19.9 \\
\hline Richest & 1053 & 16.5 & 1619 & 19.5 \\
\hline \multicolumn{5}{|l|}{ Religion } \\
\hline Islam & 5876 & 92.2 & 7644 & 92.0 \\
\hline Others & 499 & 7.8 & 668 & 8.0 \\
\hline \multicolumn{5}{|c|}{ Residential status } \\
\hline Urban & 1253 & 19.7 & 2241 & 27.0 \\
\hline Rural & 5122 & 80.4 & 6071 & 73.0 \\
\hline \multicolumn{5}{|l|}{ Region } \\
\hline Barisal & 379 & 5.9 & 461 & 5.6 \\
\hline Chittagong & 1400 & 22.0 & 1744 & 21.0 \\
\hline Dhaka & 1967 & 30.9 & 2814 & 33.9 \\
\hline Khulna & 684 & 10.7 & 767 & 9.2 \\
\hline Rajshahi & 1417 & 22.2 & 1848 & 22.2 \\
\hline Sylhet & 528 & 8.3 & 678 & 8.2 \\
\hline Total & 6375 & 100.0 & 8312 & 100.0 \\
\hline
\end{tabular}

\section{Results from logistic regression analysis for stunting} among children below five years (Table 3) 2017-18

Estimates from logistic regression analysis showed that the likelihood of stunting among under-five children was $46 \%$ significantly less in 2017-18 than 2004 [AOR: 0.54; CI: 0.49-0.59]. Similarly, the odds of stunting were $29 \%$ significantly less among children whose mother did not have low BMI compared to their counterparts [AOR: 0.71; CI: $0.66-0.78]$. The likelihood of stunting was $18 \%$ less likely to occur among children whose fathers were educated than those whose fathers did not receive any formal education [AOR: 0.82; CI: 0.75-0.90]. Moreover, children in the age range of 23-47 months [AOR: 1.85; CI: 1.71-2.01] and 48-59 months [AOR: 1.35; CI: $1.22-$ 1.49] had $85 \%$ and $35 \%$ higher likelhood of being stunted with reference to children in the age of 0-23 months. Similarly, children's from birth order of 4 or more were $24 \%$ significnalty more likely to be stunted in reference to children from birth order as one [AOR: 1.24; CI: 1.11-1.38]. The odds of stunting was lower among those households who had improved toilets than those who did not used [AOR: 0.92; CI: 0.84-1.06]. The odds of stunting among children decreased with the increase of wealth of the household. Moreover, the likelihood of stunting was $22 \%$ less among children who belonged to other religion group compared to children who belonged to Islam religion [AOR: 0.88; CI: 0.77-1.08]. Sylhet region had $30 \%$ higher likelihood of stunting among children with reference to Barisal region [AOR: 1.30; CI: $1.12-1.51]$.

\section{Estimates from decomposition analysis for stunting} among children (Table 4)

Table 4 provides the estimates of decomposition analysis for the change in stunting among U5 children from 2004 to 2017-18 in Bangladesh. Fairlie decomposition analysis was used to find out the factors which contributed towards the increment or decrement of the prevalence of stunting between 2004 to 2017-18. Overall, selected variables could explain $50.6 \%$ of the decrease in the prevalence of stunting. A contribution with a positive sign shows that a particular factor has increased the prevalence of stunting between 2004 and 2017-18. However, if the contribution is negative, that means a decline in the prevalence of stunting was observed. Mother's characteristics $(29.4 \%)$ were the primary contributors explaning the change in the prevalence of stunting from 2004 to 2017-18 followed by father's characteristics (9\%). Moreover, within the mother's characteristics, body mass index of mother (13.7\%) followed by their educational status (10.5\%) contributed most towards the change in the stunting from 2004 to 2017-18. Among father's characteristics, educational status of father (9\%) was the prime factor towards the change in stunting among children age below 5 year. Birth order was the major contributor $(3.9 \%)$ towards the change in the prevalence of stunting among children.

\section{Discussion}

Since stunting replicates the accumulative outcome of socio-economic, health and nutritional drawbacks that 
Table 2 Prevalence of stunting among children aged under five years by background characteristics in Bangladesh

\begin{tabular}{|c|c|c|c|c|}
\hline Background characteristics & $2004(\%)$ & 2017-18 (\%) & Difference & $p$-value \\
\hline \multicolumn{5}{|l|}{ Mother's characteristics } \\
\hline \multicolumn{5}{|l|}{ Age at first birth } \\
\hline Less than 18 years & 51.7 & 33.5 & -18.2 & $<0.001$ \\
\hline 18 years or more & 47.0 & 28.6 & -18.4 & $<0.001$ \\
\hline \multicolumn{5}{|l|}{ Educational status } \\
\hline Not educated & 57.5 & 42.9 & -14.6 & $<0.001$ \\
\hline Educated & 45.2 & 29.8 & -15.5 & $<0.001$ \\
\hline \multicolumn{5}{|l|}{ Working status } \\
\hline Not working & 49.5 & 28.3 & -21.2 & $<0.001$ \\
\hline Working & 51.5 & 34.0 & -17.6 & $<0.001$ \\
\hline \multicolumn{5}{|l|}{ Low BMI } \\
\hline No & 45.6 & 29.0 & -16.6 & $<0.001$ \\
\hline Yes & 56.7 & 40.7 & -16.0 & $<0.001$ \\
\hline \multicolumn{5}{|l|}{ Father's characteristics } \\
\hline \multicolumn{5}{|l|}{ Educational status } \\
\hline Not educated & 56.5 & 43.6 & -12.9 & $<0.001$ \\
\hline Educated & 45.4 & 28.5 & -16.9 & $<0.001$ \\
\hline \multicolumn{5}{|l|}{ Working status } \\
\hline Not working & 44.0 & 34.0 & -10.0 & $<0.001$ \\
\hline Working & 49.9 & 30.6 & -19.3 & $<0.001$ \\
\hline \multicolumn{5}{|l|}{ Child's characteristics } \\
\hline \multicolumn{5}{|l|}{ Children age (in months) } \\
\hline $0-23$ & 39.0 & 26.9 & -12.0 & $<0.001$ \\
\hline $23-47$ & 58.6 & 36.1 & -22.5 & $<0.001$ \\
\hline $48-59$ & 53.6 & 28.4 & -25.2 & $<0.001$ \\
\hline \multicolumn{5}{|l|}{ Sex } \\
\hline Male & 50.6 & 30.8 & -19.8 & $<0.001$ \\
\hline Female & 49.1 & 30.7 & -18.4 & $<0.001$ \\
\hline \multicolumn{5}{|l|}{ Birth order } \\
\hline 1 & 47.9 & 28.7 & -19.1 & $<0.001$ \\
\hline 2 & 45.5 & 28.5 & -17.1 & $<0.001$ \\
\hline 3 & 48.2 & 32.0 & -16.2 & $<0.001$ \\
\hline 4 and above & 57.0 & 41.0 & -16.1 & $<0.001$ \\
\hline \multicolumn{5}{|l|}{ Household characteristics } \\
\hline \multicolumn{5}{|l|}{ Protected water source } \\
\hline No & 55.0 & 28.7 & -26.3 & $<0.001$ \\
\hline Yes & 49.7 & 31.1 & -18.6 & $<0.001$ \\
\hline \multicolumn{5}{|l|}{ Improved toilet facility } \\
\hline No & 56.9 & 34.3 & -22.6 & $<0.001$ \\
\hline Yes & 44.4 & 28.1 & -16.3 & $<0.001$ \\
\hline \multicolumn{5}{|l|}{ Wealth Index } \\
\hline Poorest & 60.8 & 40.3 & -20.5 & $<0.001$ \\
\hline Poorer & 54.5 & 37.3 & -17.2 & $<0.001$ \\
\hline Middle & 49.5 & 30.1 & -19.4 & $<0.001$ \\
\hline
\end{tabular}


Table 2 Prevalence of stunting among children aged under five years by background characteristics in Bangladesh (Continued)

\begin{tabular}{|c|c|c|c|c|}
\hline Background characteristics & $2004(\%)$ & 2017-18 (\%) & Difference & $p$-value \\
\hline Richer & 47.6 & 26.7 & -21.0 & $<0.001$ \\
\hline Richest & 30.2 & 17.2 & -13.0 & $<0.001$ \\
\hline \multicolumn{5}{|l|}{ Religion } \\
\hline Islam & 50.4 & 30.9 & -19.5 & $<0.001$ \\
\hline Others & 43.5 & 28.8 & -14.7 & $<0.001$ \\
\hline \multicolumn{5}{|l|}{ Residential status } \\
\hline Urban & 44.2 & 25.3 & -18.8 & $<0.001$ \\
\hline Rural & 51.2 & 32.7 & -18.6 & $<0.001$ \\
\hline \multicolumn{5}{|l|}{ Region } \\
\hline Barisal & 55.3 & 32.8 & -22.5 & $<0.001$ \\
\hline Chittagong & 52.4 & 32.5 & -19.9 & $<0.001$ \\
\hline Dhaka & 51.3 & 27.9 & -23.4 & $<0.001$ \\
\hline Khulna & 40.6 & 25.6 & -15.0 & $<0.001$ \\
\hline Rajshahi & 47.2 & 30.6 & -16.5 & $<0.001$ \\
\hline Sylhet & 52.9 & 42.4 & -10.5 & $<0.001$ \\
\hline Total & 49.8 & 30.7 & -19.1 & $<0.001$ \\
\hline
\end{tabular}

p-value based on proportion test

vary over time $[39,40]$, the continuous evaluation of underlying factors may help boost the pace of its reduction. In spite of substantial achievements in reducing the prevalence rates of stunting among under-five children in Bangladesh through various intervention programs, the findings of this study with $30.7 \%$ children still being stunted with marked regional variations underscore the need for further improvement in the children's nutritional status in the country.
In the present study, we found that children of age group 23-47 months, with higher birth order, born to mothers with low BMI, to mothers and fathers with no formal education and belonging to households with poor sanitation and poorest wealth index were significantly more likely to be stunted. Results from binary logistic regression show that as children grow up they become more likely to be stunted. Similarly, under five children who were most likely to be stunted belonged to the age

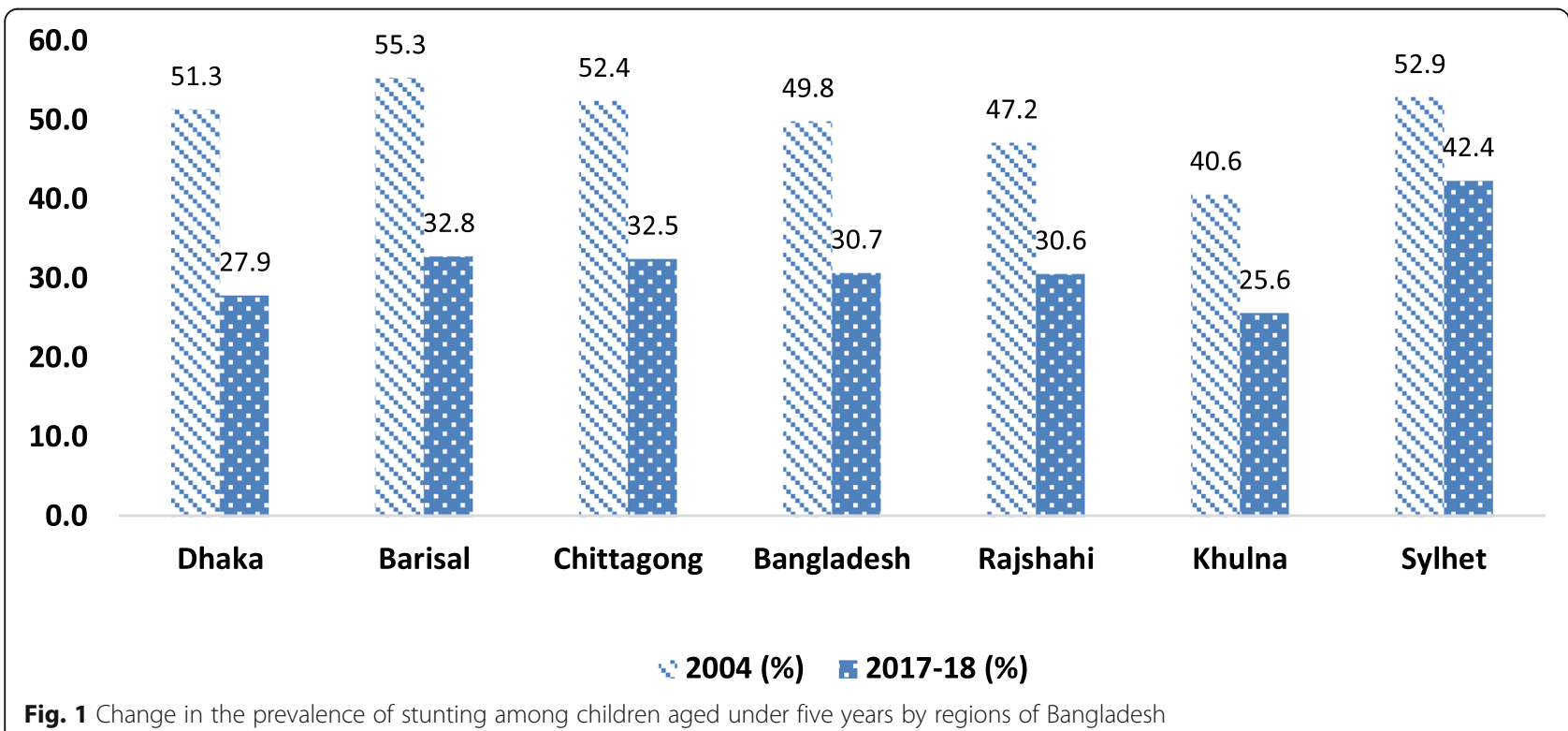


Table 3 Logistic regression estimates for stunting aged under five by background characteristics in Bangladesh

\begin{tabular}{l} 
Background characteristics \\
\hline Year \\
2004 \\
$2017-18$ \\
Mother's characteristics \\
Age at first birth \\
Less than 18 years \\
18 years or more \\
Educational status \\
Not educated \\
Educated \\
Working status \\
Not working \\
Working \\
Low BMI \\
No \\
Yes
\end{tabular}

Father's characteristics

Educational status

Not educated

Educated

Working status

Not working

Working

Child's characteristics

Children age (in months)

$0-23$

23-47

48-59

Sex

Male

Female

Birth order

1

2

3

4 and above

Household characteristics

Protected water source

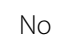

Yes

Improved toilet facility

No

Yes
$\operatorname{AOR}(95 \% \mathrm{Cl})$

Ref.

$0.54 *(0.49,0.59)$

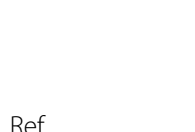

$0.95(0.88,1.02)$

Ref.

$0.92(0.83,1.02)$

Ref.

1.04(0.96,1.13)

$0.71 *(0.66,0.78)$

Ref.

Ref.

$0.82 *(0.75,0.90)$

Ref.

1.04(0.8,1.37)

Ref.

$1.85 *(1.71,2.01)$

$1.35 *(1.22,1.49)$

Ref.

$1.00(0.93,1.08)$

Ref.

$0.96(0.87,1.05)$

$1.01(0.91,1.13)$

$1.24 *(1.11,1.38)$

Ref.

$1.00(0.88,1.14)$

Ref.

$0.92 *(0.84,1.06)$
Table 3 Logistic regression estimates for stunting aged under five by background characteristics in Bangladesh (Continued)

\begin{tabular}{ll}
\hline Background characteristics & AOR(95\% Cl) \\
\hline Wealth Index & \\
Poorest & Ref. \\
Poorer & $0.93(0.83,1.04)$ \\
Middle & $0.75^{*}(0.67,0.85)$ \\
Richer & $0.67^{*}(0.59,0.75)$ \\
Richest & $0.35^{*}(0.3,0.4)$ \\
Religion & \\
Islam & Ref. \\
Others & $0.88^{*}(0.77,1.08)$ \\
Residential status & \\
Urban & Ref. \\
Rural & $0.93(0.86,1.02)$ \\
Region & \\
Barisal & $\operatorname{Ref.}$ \\
Chittagong & $1.09(0.95,1.25)$ \\
Dhaka & $0.94(0.82,1.08)$ \\
Khulna & $0.75^{*}(0.64,0.87)$ \\
Rajshahi & $0.77^{*}(0.67,0.88)$ \\
Sylhet & $1.30^{*}(1.12,1.51)$ \\
\hline${ }^{*} p<0.05 ; A O R$ Adjusted Odds Ratio, Cl Confidence Interval, Ref \\
Reference category
\end{tabular}

of $23-47$ months. And the result is consistent with recent studies in Bangladesh [16, 41, 42]. Higher prevalence of stunting among children who aged 2 year and older can be explained by inapropriated or untimely initiation of complementary feeding and lack of dietary diversity and nutritional knowledge that are found to be major risk factors of stunting [43, 44]. Furthermore, the finding that fifth or higher order birth is related to a greater prevalence of stunting is similar to another study in Bengladesh [45], and is so probably due to lesser time to extend care equally to each of the children. It is also noted that having a higher number of siblings in a household may cause growth retardation in children due to competition for limited available nutritional resources [46]. However, the decadel decline in children with higher birth order possibly due to declining fertility and growing number of small-sized families has significantly contributed to the observed decrease in childhood stunting in the present study.

Studies in low-and-middle income countries reveal that the child is inherited with how he/she was cared both in the womb and during childhood and there exists an intergenerational cycle of health and nutrition [4749]. The study result suggests that healthier mothers have lower risk of having stunted children. The finding that the maternal higher BMI as a protective predictor 
Table 4 Decomposition estimates for stunting among children aged under five in Bangladesh, 2004 to 2017-18

\begin{tabular}{|c|c|c|c|c|}
\hline Background characteristics & Coef. & Std. error & $p$-value & $\%$ Contribution \\
\hline \multicolumn{5}{|l|}{ Mother characteristics } \\
\hline \multicolumn{5}{|l|}{ Age at first birth } \\
\hline Less than 18 years & Ref. & & & \\
\hline 18 years or more & 0.003 & 0.002 & 0.063 & 1.6 \\
\hline \multicolumn{5}{|l|}{ Educational status } \\
\hline Not educated & Ref. & & & \\
\hline Educated & 0.020 & 0.004 & 0.000 & 10.5 \\
\hline \multicolumn{5}{|l|}{ Working status } \\
\hline Not working & Ref. & & & \\
\hline Working & 0.007 & 0.002 & 0.006 & 3.6 \\
\hline \multicolumn{5}{|l|}{ Low BMI } \\
\hline No & Ref. & & & \\
\hline Yes & 0.026 & 0.003 & 0.000 & 13.7 \\
\hline \multicolumn{5}{|l|}{ Father characteristics } \\
\hline \multicolumn{5}{|l|}{ Educational status } \\
\hline Not educated & Ref. & & & \\
\hline Educated & 0.017 & 0.003 & 0.000 & 9.0 \\
\hline \multicolumn{5}{|l|}{ Working status } \\
\hline Not working & Ref. & & & \\
\hline Working & 0.000 & 0.000 & 0.969 & 0.0 \\
\hline \multicolumn{5}{|l|}{ Child characteristics } \\
\hline \multicolumn{5}{|l|}{ Children age (in months) } \\
\hline $0-23$ & Ref. & & & \\
\hline $23-47$ & 0.000 & 0.000 & 0.000 & 0.2 \\
\hline $48-59$ & 0.001 & 0.000 & 0.000 & 0.6 \\
\hline \multicolumn{5}{|l|}{ Sex } \\
\hline Male & Ref. & & & \\
\hline Female & 0.000 & 0.000 & 0.971 & 0.0 \\
\hline \multicolumn{5}{|l|}{ Birth order } \\
\hline 1 & Ref. & & & \\
\hline 2 & 0.001 & 0.001 & 0.117 & 0.6 \\
\hline 3 & 0.000 & 0.000 & 0.721 & 0.0 \\
\hline 4 and above & 0.007 & 0.002 & 0.000 & 3.9 \\
\hline \multicolumn{5}{|l|}{ Household characteristics } \\
\hline \multicolumn{5}{|l|}{ Protected water source } \\
\hline No & Ref. & & & \\
\hline Yes & 0.004 & 0.002 & 0.003 & 2.3 \\
\hline \multicolumn{5}{|l|}{ Improved toilet facility } \\
\hline No & Ref. & & & \\
\hline Yes & 0.001 & 0.000 & 0.155 & 0.3 \\
\hline \multicolumn{5}{|l|}{ Wealth Index } \\
\hline Poorest & Ref. & & & \\
\hline Poorer & 0.000 & 0.000 & 0.694 & -0.1 \\
\hline Middle & -0.001 & 0.000 & 0.405 & -0.5 \\
\hline
\end{tabular}


Table 4 Decomposition estimates for stunting among children aged under five in Bangladesh, 2004 to $2017-18$ (Continued)

\begin{tabular}{|c|c|c|c|c|}
\hline Background characteristics & Coef. & Std. error & $p$-value & $\%$ Contribution \\
\hline Richer & 0.001 & 0.000 & 0.000 & 0.6 \\
\hline Richest & 0.008 & 0.001 & 0.000 & 4.0 \\
\hline \multicolumn{5}{|l|}{ Religion } \\
\hline Islam & Ref. & & & \\
\hline Others & 0.000 & 0.000 & 0.201 & 0.1 \\
\hline \multicolumn{5}{|l|}{ Residential status } \\
\hline Urban & Ref. & & & \\
\hline Rural & 0.000 & 0.001 & 0.952 & 0.0 \\
\hline \multicolumn{5}{|l|}{ Region } \\
\hline Barisal & Ref. & & & \\
\hline Chittagong & 0.000 & 0.000 & 0.740 & 0.0 \\
\hline Dhaka & 0.001 & 0.000 & 0.045 & 0.4 \\
\hline Khulna & 0.001 & 0.000 & 0.005 & -0.4 \\
\hline Rajshahi & 0.000 & 0.000 & 0.143 & 0.2 \\
\hline \multirow[t]{2}{*}{ Sylhet } & 0.000 & 0.000 & 0.563 & 0.0 \\
\hline & & & & 50.6 \\
\hline N (2004) & 6003 & & & \\
\hline N (2018) & 7849 & & & \\
\hline Predictive probability of being stunted in 2004 (p1) & 0.498 & & & \\
\hline Predictive probability of being stunted in 2017-18 (p2) & 0.307 & & & \\
\hline Difference (p1-p2) & 0.191 & & & \\
\hline Total explained & 0.097 & & & \\
\hline
\end{tabular}

for childhood stunting is consistent with previous studies [50-52]. It is argued that with good nutritional status, mothers can confirm better breastfeeding and react to pregnancy-related stressors effectively [42, 53]. In addition, current study found that mother's low BMI had a significant and largest contribution to decadel decrease in childhood stunting compared to all other factors. It reflects the findings of recent studies in Bengladesh on the success of delivering multiple interventions for maternal nutrition and health [54-56].

Education of parents is found to be another significant contributer to the decrease in the prevalence of stunting among the children below 5 years, indicating the improvements in overall socioeconomic indicators of the general population in the country. Again, education being a significant predictor shows that higher levels of education can act as a preventive factor against child stunting. Thus, children may become stunted due to their mothers' or fathers' lower educational status and lack of sources of knowledge on child nutrition. Evidence suggests that education always plays a positive role in health and diseases $[57,58]$. Studies conducted in low and middle income countries also reveal that educated mothers tend to be older at their first birth and are more knowledgeable about health, nutrition, hygiene and care practices for children [59-61]. In addition, a recent study shows that maternal awareness on childfeeding practices also led to improved nutritional status of young children [62]. Educated parents can further contribute to a better household economic status that is supportive of providing sufficient nutritional diet to their children. Additionally, they tend to have have greater access to media that make them better able to use available health-care facilities and more adept at keeping their environment clean $[52,63]$.

Furthermore, nutritional status of children is considered as an indicator that reflects the household economic condition. This study also shows that children from households with poorest wealth index are most likely to be stunted in consistence with previous studies conducted in other countries [42, 61, 64, 65]. This can be attributed to the fact that households with higher socioeconomic status may have more ability to allocate necessary resources regarding nutrition for their children. Also, reasonable allocation of resources may improve their children's health conditions by minimizing multiple health risks. Consistent with past studies [15, 60, 66], access to improved toilet facility in the households was found as a significant determinant of stunting among under-five children. Poor sanitation facilities have 
negative impact on child's nutritional status through pathways such as loss of appetite, loss of host tissues and maldigestion, resulting in a vicious cycle of growth faltering in childhood [67]. It is also documented that an adverse environment may cause differences in the metabolism of micronutrients in children and potentially limit their ability to develop into healthy adults $[30,68]$.

Finally, we observed large regional variations in the prevalence of stunting among under-five children, where highest prevalence was found in the Sylhet administrative division. Although the Sylhet division is established in previous studies as poorest performing region in most of the health-related indicators including child stunting $[52,69]$, the situation still remains the same. Thus, region specific studies are warranted for seeking explanations of why the stunting of Bengladeshi children varies across different divisions.

This study has certain limitations. Firstly, the study was based on cross-sectional data, which failed to establish a casual relationship. Importantly, the study assumes that stunting is due primarily to nutrition and any of the nutritional variables were not included in the analysis. Another major limitation is that this study has particularly focused only some selected factors. The factors, such as duration of breast feeding, household size, use of iodized salt and dietary diversity, among others that may also affect stunting among children were not analysed.

The strenths of this study the results identified the most vital risk factors of stunting, which will add to the available literature on the association of socioeconomic and demographic variables and parents' characteristics with stunting of under five children in Bengladesh. Besides, the survey data used in the present analysis was based on a two-stage stratified sampling of households and was designed to generate representative results for the country as a whole and for each of the seven administrative divisions.

\section{Conclusion}

The results of the study strongly highlight the importance of taking steps to make people educated and to reduce household wealth inequality to improve nutritional status of children. In order to achieve further reduction in stunting among under-five children in Bangladesh, target interventions that would benefit the socioeconomically backward population are required. Results also suggest that the policymakers should develop an effective program to improve the maternal education and health and increase awareness of parents about the standard children's height and weight according to their age and gender. Despite making gains in macro level health and development indicators, there is a need to address the underlying issues of child malnutrition in Bangladesh. Therefore, policymakers need to revisit and expand current mother-child specific programs and interventions targeting vulnerable regions and households. Also, government may take necessary steps to make women of reproductive age aware about adverse effects of higher birth order in their later ages and its adverse effects on child health.

\section{Abbrevations}

BDHS: Bangladesh Demographic and Health Survey; NIPORT: National Institute for Population Research and Training; EA: Enumeration Area; PSU: Primary Sampling Unit; BBS: Bangladesh Bureau of Statistics;

SD: Standard Deviation; WHO: World Health Organization; AOR: Adjusted Odds Ratio; Cl: Confidence Interval

\section{Acknowledgments}

Not applicable.

Authors' contributions

The concept was drafted by SS; SS and PK contributed to the analysis design; SS, PK, MT and RR advised on the paper and assisted in paper conceptualization; MT and RR contributed to the comprehensive writing of the article. All authors read and approved the final manuscript.

\section{Authors' information}

Pradeep Kumar completed his M.Phil. in Population studies and currently pursuing his PhD in Population studies from International Institute for Population Sciences, Mumbai, India. His area of interest is Ageing and reproductive health among married women in India.

Rashmi Rashmi is currently a doctoral scholar at the Department of Mathematical Demography and Statistics of the International Institute for Population Sciences, Mumbai, India. She completed her post-graduation in Biostatistics and Demography from IIPS, Mumbai.

Muhammad T completed his M.Phil. in Population studies and currently pursuing his $\mathrm{PhD}$ in Population studies from International Institute for Population Sciences, Mumbai, India. His area of interest includes maternal and child health, health disparities among vulnerable populations and population ageing.

Shobhit Srivastava completed his M.Phil. in Population studies and currently pursuing his PhD in Population studies at International Institute for Population Sciences, Mumbai, India. His area of interest is public health issues in India.

\section{Funding}

Authors did not receive any funding to carry out this research.

Availability of data and materials

The study utilizes a secondary source of data that is freely available in the public domain through, https://dhsprogram.com/data/dataset/Bangladesh_ Standard-DHS_2017.cfm?flag=1

\section{Declarations}

\section{Ethics approval and consent to participate}

The data is freely available in the public domain and survey agencies that conducted the field survey for the data collection have collected prior consent from the respondent. The local ethics committee of the International Institute for Population Sciences [IIPS], Mumbai, ruled that no formal ethics approval was required to carry out research from this data source. All methods were performed in accordance with the relevant guidelines and regulations. Informed consent obtained from the respondents.

Consent for publication

Not applicable.

Competing interests

The authors declare that they have no competing interests. 
Received: 26 April 2021 Accepted: 8 November 2021 Published online: 16 November 2021

\section{References}

1. Liu L, Oza S, Hogan D, Chu Y, Perin J, Zhu J, et al. Global, regional, and national causes of under-5 mortality in 2000-15: an updated systematic analysis with implications for the sustainable development goals. Lancet. 2016;388(10063):3027-35. https://doi.org/10.1016/S0140-6736(16)31593-8.

2. Mosley WH. Child survival: research and policy. Popul Dev Rev. 1984;10:3-23. https://doi.org/10.2307/2807953.

3. Mosley $\mathrm{WH}$, Chen LC. An analythical framework for the study of child survival in developing countries. Bull World Health Organ. 2003;81(2):140-5.

4. Victora CG, Requejo JH, Barros AJD, Berman P, Bhutta Z, Boerma T, et al. Countdown to 2015: a decade of tracking progress for maternal, newborn, and child survival. Lancet. 2016;387(10032):2049-59. https://doi.org/10.1016/ S0140-6736(15)00519-X.

5. Keeley B, Cãš L, Zuehlke E. The State of the World's Children 2019: Children, food and nutrition--growing well in a changing world. UNICEF; 2019.

6. Black MM, Walker SP, Fernald LCH, Andersen CT, DiGirolamo AM, Lu C, et al. Early childhood development coming of age: science through the life course. Lancet. 2017;389(10064):77-90. https://doi.org/10.1016/S0140-6736(1 6)31389-7.

7. De Haen H, Klasen S, Qaim M. What do we really know? Metrics for food insecurity and undernutrition. Food Policy. 2011;36(6):760-9. https://doi. org/10.1016/j.foodpol.2011.08.003

8. World Health Organization. Stunting in a nutshell [Internet]. [cited 2021 Sep 29]. Available from: https://www.who.int/news/item/19-11-2015-stuntingin-a-nutshell

9. UNICEF. Global Overview Child Malnutrition Regional Trends. Unicef. 2019;

10. Chowdhury FR, Ibrahim QSU, Bari MS, Alam MMJ, Dunachie SJ, RodriguezMorales AJ, et al. The association between temperature, rainfall and humidity with common climate-sensitive infectious diseases in Bangladesh. PLoS One. 2018;13(6):e0199579. https://doi.org/10.1371/journal.pone.01 99579.

11. Bene C, Waid J, Jackson-deGraffenried M, Begum A, Chowdhury M, Skarin V, et al. Impact of climate-related shocks and stresses on nutrition and food security in selected areas of rural Bangladesh. Dhaka World Food Programme. 2015;3.

12. Rabbani A, Khan A, Yusuf S, Adams A. Trends and determinants of inequities in childhood stunting in Bangladesh from 1996/7 to 2014. Int J Equity Health. 2016;15(1):186. https://doi.org/10.1186/s12939-016-0477-7.

13. NIPORT and ICF. Bangladesh Demographic and Health Survey 2017-18: Key Indicators. 2019.

14. WFP. World Food Programme Bangladesh Nutrition Strategy 2012-2016: World Food Programme Bangladesh; 2012.

15. Kamal SM. Socio-economic determinants of severe and moderate stunting among under-five children of rural Bangladesh. Malays J Nutr. 2011;17(1).

16. Sultana P, Rahman MM, Akter J. Correlates of stunting among under-five children in Bangladesh: a multilevel approach. BMC Nutr. 2019;5(1):41. https://doi.org/10.1186/s40795-019-0304-9.

17. Saha UR, Chattopadhyay A, Richardus JH. Correction: trends, prevalence and determinants of childhood chronic undernutrition in regional divisions of Bangladesh: evidence from demographic health surveys, 2011 and 2014 PLoS One. 2020;15(2):e0229677. https://doi.org/10.1371/journal.pone.022 9677.

18. Wali N, Agho KE, Renzaho A. Factors associated with stunting among children under 5 years in five south Asian countries (2014-2018): analysis of demographic health surveys. Nutrients. 2020;12(12):3875. https://doi.org/1 0.3390/nu12123875.

19. Sarma H, Khan JR, Asaduzzaman M, Uddin F, Tarannum S. Hasan MdM, et al. factors influencing the prevalence of stunting among children aged below five years in Bangladesh. Food Nutr Bull. 2017;38(3):291-301. https://doi. org/10.1177/0379572117710103.

20. Islam A, Biswas T. Chronic stunting among under-5 children in Bangladesh: a situation analysis. Adv Pediatr Res. 2015;2(18):1-9.

21. Caulfield LE, Richard SA, Rivera JA, Musgrove P, Black RE. Stunting, wasting, and micronutrient deficiency disorders. In: Disease Control Priorities in Developing Countries 2nd edition: The International Bank for Reconstruction and Development/The World Bank; 2006
22. Martins VJB, Toledo Florêncio TMM, Grillo LP, Do Carmo P Franco M, Martins PA, Clemente APG, et al. Long-lasting effects of undernutrition. Int J Environ Res Public Health. 2011;8(6):1817-46. https://doi.org/10.3390/ijerph8061817.

23. Paul $R$, Singh A. Does early childhood adversities affect physical, cognitive and language development in indian children? Evidence from a panel study. SSM Popul Health. 2020;12:100693. https://doi.org/10.1016/j.ssmph.2 020.100693

24. Leroy JL, Frongillo EA. Perspective: what does stunting really mean? A critical review of the evidence. Adv Nutr. 2019;10(2):196-204. https://doi. org/10.1093/advances/nmy101.

25. De Onis M, Branca F. Review Article Childhood stunting : a global perspective. 2016;12:12-26. https://doi.org/10.1111/mcn.12231.

26. UNCF. Strategy for improved nutrition of children and women in developing countries. Indian J Pediatr. 1991;58:13-24.

27. Aguayo VM, Menon P. Stop stunting: improving child feeding, women's nutrition and household sanitation in South Asia. Maternal Child Nutr. 2016; 12:3-11. https://doi.org/10.1111/mcn.12283.

28. Hong R, Banta JE, Betancourt JA. Relationship between household wealth inequality and chronic childhood under-nutrition in Bangladesh. Int J Equity Health. 2006;5(1):15. https://doi.org/10.1186/1475-9276-5-15.

29. Hossain MS, Ferdous S, Raheem E, Siddiqee MH. The double burden of malnutrition - further perspective. Lancet. 2020;396(10254):813-4. https:// doi.org/10.1016/S0140-6736(20)31359-3.

30. Humphrey $\mathrm{JH}$. Child undernutrition, tropical enteropathy, toilets, and handwashing. Lancet. 2009;374(9694):1032-5. https://doi.org/10.1016/S01406736(09)60950-8.

31. Headey DD. Developmental drivers of nutritional change: a cross-country analysis. World Dev. 2013;42:76-88. https://doi.org/10.1016/j.worlddev.2012. 07.002 .

32. Headey D, Hoddinott J, Ali D, Tesfaye R, Dereje M. The other Asian enigma: explaining the rapid reduction of undernutrition in Bangladesh. World Dev. 2015;66:749-61. https://doi.org/10.1016/j.worlddev.2014.09.022.

33. Fairlie RW. An extension of the blinder-Oaxaca decomposition technique to logit and probit models. J Econ Soc Meas. 2019;30(4):305-16. https://doi. org/10.3233/JEM-2005-0259.

34. NIPORT. Bangladesh Demograph and Health Survey. In: Bangladesh Demographic and Health Survey 2017-18; 2020.

35. NIPORT. Bangladesh Demograph and Health Survey. In: Bangladesh Demographic and Health Survey 2004; 2005.

36. Singh SK, Srivastava S, Chauhan S. Inequality in child undernutrition among urban population in India: a decomposition analysis. BMC Public Health. 2020;20(1):1852. https://doi.org/10.1186/s12889-020-09864-2.

37. Jann B. The blinder-Oaxaca decomposition for linear regression models. Stata J. 2008;8(4):453-79. https://doi.org/10.1177/1536867X0800800401.

38. StataCorp. Stata: Release 14. Statistical Software. College Station: StataCorp LP; 2015.

39. Wamani H, Åstrøm AN, Peterson S, Tumwine JK, Tylleskär T. Boys are more stunted than girls in sub-Saharan Africa: a meta-analysis of 16 demographic and health surveys. BMC Pediatr. 2007;7(1):1-10. https://doi.org/10.1186/14 71-2431-7-17.

40. Kennedy G, Nantel G, Brouwer ID, Kok FJ. Does living in an urban environment confer advantages for childhood nutritional status? Analysis of disparities in nutritional status by wealth and residence in Angola, Central African Republic and Senegal. Public Health Nutr. 2006;9(2):187-93. https:// doi.org/10.1079/PHN2005835.

41. Das S, Gulshan J. Different forms of malnutrition among under five children in Bangladesh: a cross sectional study on prevalence and determinants. BMC Nutr. 2017;3(1):1-12. https://doi.org/10.1186/s40795016-0122-2.

42. Talukder A. Factors associated with malnutrition among under-five children: illustration using Bangladesh demographic and health Survey, 2014 data. Children. 2017:4(10):88. https://doi.org/10.3390/children4100088.

43. Menon P, Bamezai A, Subandoro A, Ayoya MA, Aguayo V. Age-appropriate infant and young child feeding practices are associated with child nutrition in India: insights from nationally representative data. Matern Child Nutr. 2015:11(1):73-87. https://doi.org/10.1111/mcn.12036.

44. Ahmed AS, Ahmed T, Roy SK, Alam N, Hossain MI. Determinants of undernutrition in children under 2 years of age from rural Bangladesh. Indian Pediatr. 2012;49(10):821-4. https://doi.org/10.1007/s13312-012-0187-2.

45. Rahman M. Association between order of birth and chronic malnutrition of children : a study of nationally representative Bangladeshi sample. Cad 
Saude Publica. 2016;32(2):e00011215. https://doi.org/10.1590/0102-311 X00011215.

46. Horton S. Birth order and child nutritional status : evidence from the Philippines. Econ Dev Cult Chang. 1988;36(2):341-54. https://doi.org/10.1 086/451655

47. Li Z, Kim R, Vollmer S, Subramanian SV. Factors associated with child stunting, wasting, and underweight in 35 low- and middle-income countries. JAMA Netw Open. 2020;3(4):e203386. https://doi.org/10.1001/ja manetworkopen.2020.3386.

48. Ferreira HS, Moura FA, Cabral Júnior CR, Florêncio TMMT, Vieira RC, de Assunção ML. Short stature of mothers from an area endemic for undernutrition is associated with obesity, hypertension and stunted children: a population-based study in the semi-arid region of Alagoas, Northeast Brazil. Br J Nutr. 2009;101(8):1239-45. https://doi.org/10.1017/ S0007114508059357.

49. Heslehurst N, Simpson H, Ells LJ, Rankin J, Wilkinson J, Lang R, et al. The impact of maternal BMI status on pregnancy outcomes with immediate short-term obstetric resource implications: a meta-analysis. Obes Rev. 2008 9(6):635-83. https://doi.org/10.1111/j.1467-789X.2008.00511.x.

50. Santos Felisbino-Mendes M, Villamor E, Velasquez-Melendez G. Association of maternal and child nutritional status in Brazil: a population based crosssectional study. PLoS One. 2014;9(1):1-8. https://doi.org/10.1371/journal. pone.0087486

51. Tigga PL, Sen J. Maternal body mass index is strongly associated with children ? J Anthropol. 2016;2016:2-10. https://doi.org/10.1155/2016/653823 5 .

52. Akram R, Sultana M, Ali N, Sheikh N, Sarker AR. Prevalence and determinants of stunting among preschool children and its urban-rural disparities in Bangladesh. Food Nutr Bull. 2018;39(4):521-35. https://doi.org/10.1177/03 79572118794770.

53. Dekker LH, Mora-plazas M, Marín C, Baylin A, Villamor E. Stunting associated with poor socioeconomic and maternal nutrition status and respiratory morbidity in Colombian schoolchildren. 2010;31(2):242-50. https://doi.org/1 $0.1177 / 156482651003100207$

54. El Arifeen S, Hill K, Ahsan KZ, Jamil K, Nahar Q, Streatfield PK. Maternal mortality in Bangladesh: a countdown to 2015 country case study. Lancet. 2014;384(9951):1366-74. https://doi.org/10.1016/S0140-6736(14)60955-7.

55. Nguyen PH, Kim SS, Sanghvi T, Mahmud Z, Tran LM, Shabnam S, et al. Integrating nutrition interventions into an existing maternal, neonatal, and child health program increased maternal dietary diversity, micronutrient intake, and exclusive breastfeeding practices in Bangladesh: results of a cluster-randomized program eval. J Nutr. 2017;147(12):2326-37. https://doi. org/10.3945/jn.117.257303.

56. Haider MR, Rahman MM, Rahman E, Ahmed S, Khan MM. Impact of maternal and neonatal health initiatives on inequity in maternal health care utilization in Bangladesh. 2017;(Ci):1-15.

57. Rahman MM, Saima U, Goni MA. Impact of maternal household decisionmaking autonomy on child nutritional status in Bangladesh. Asia Pac J Public Health. 2015;27(5):509-20. https://doi.org/10.1177/1010539514568710.

58. Rahman MS, Howlader T, Masud MS, Rahman ML. Association of low-birth weight with malnutrition in children under five years in Bangladesh: do mother's education, socio-economic status, and birth interval matter? PLoS One. 2016;11(6):1-16. https://doi.org/10.1371/journal.pone.0157814.

59. El Taguri A, Betilmal I, Mahmud SM, Monem Ahmed A, Goulet O, Galan P, et al. Risk factors for stunting among under-fives in Libya. Public Health Nutr. 2009;12(8):1141-9. https://doi.org/10.1017/\$1368980008003716.

60. Sarkar D, Haldar SK. Socioeconomic determinants of child malnutrition in India: evidence from NFHS-III. SSRN Electron J. 2014:1-45. https://doi.org/1 $0.2139 /$ ssrn.2420293.

61. Sah N. Determinants of child malnutrition in Nepal: a case analysis from Dhanusha, central Terai of Nepal. J Nepal Health Res Counc. 2004;2(2):50-4.

62. Mistry SK, Hossain B, Arora A. Maternal nutrition counselling is associated with reduced stunting prevalence and improved feeding practices in early childhood : a post-program comparison study. Nutrition. 2019;18(1):47. https://doi.org/10.1186/s12937-019-0473-z.

63. Sarma H, Khan JR, Asaduzzaman M, Uddin F, Tarannum S, Hasan MM, et al. Factors influencing the prevalence of stunting among children aged below five years in Bangladesh. Food Nutr Bull. 2017;38(3):291-301. https://doi. org/10.1177/0379572117710103.

64. Meshram II, Arlappa N, Balakrishna N, Mallikharjuna Rao K, Laxmaiah A, Brahmam GNV. Trends in the prevalence of undernutrition, nutrient \& food intake and predictors of undernutrition among under five year tribal children in India. Asia Pac J Clin Nutr. 2012;21(4):568-76.

65. Ruwali D. Nutritional status of children under five years of age and factors associated in Padampur VDC, Chitwan. Health Prospect. 2011;10:14-8.

66. Babatunde RO, Olagunju FI, Fakayode SB, Sola-Ojo FE. Prevalence and Determinants of Malnutrition among Under-five Children of Farming Households in Kwara State, Nigeria. J Agric Sci. 2011;3(3).

67. Torlesse H, Cronin AA, Sebayang SK, Nandy R. Determinants of stunting in Indonesian children: evidence from a cross-sectional survey indicate a prominent role for the water, sanitation and hygiene sector in stunting reduction. BMC Public Health. 2016;16(1):1-11. https://doi.org/10.1186/s12 889-016-3339-8

68. Prendergast AJ, Humphrey $\mathrm{JH}$. The stunting syndrome in developing countries. Paediatr Int Child Health. 2014;34(4):250-65. https://doi.org/10.11 79/2046905514Y.0000000158.

69. Mohsena M, Goto R, Nicholas M-TC. Regional variation in maternal and childhood undernutrition in Bangladesh: evidence from demographic and health surveys. WHO South East Asia J Public Health. 2015;4(2):139-49. https://doi.org/10.4103/2224-3151.206683.

\section{Publisher's Note}

Springer Nature remains neutral with regard to jurisdictional claims in published maps and institutional affiliations.
Ready to submit your research? Choose BMC and benefit from:

- fast, convenient online submission

- thorough peer review by experienced researchers in your field

- rapid publication on acceptance

- support for research data, including large and complex data types

- gold Open Access which fosters wider collaboration and increased citations

- maximum visibility for your research: over $100 \mathrm{M}$ website views per year

At BMC, research is always in progress.

Learn more biomedcentral.com/submissions 